\title{
Morfologia, índice meiótico, viabilidade polínica e citoquímica de Erythrina poeppigiana (Walp.) O. F. Cook
}

Erythrina poeppigiana (Walp.) O. F. Cook. é uma espécie arbórea pertencente à família Leguminosae (Papilionoideae). É consorciada em plantações de cacau por ser uma espécie caducifólia e possui potencial paisagístico devido a exuberância das flores, no entanto existem poucos estudos sobre essa espécie. O objetivo desse trabalho foi verificar a morfologia dos órgãos vegetativos e reprodutivos, índice meiótico, viabilidade polínica e composição citoquímica do grão de pólen de E. poeppigiana. Foram realizadas coletados de ramos férteis da espécie com ocorrência natural na zona rural do município de Alta Floresta, Mato Grosso. O material foi herborizado, desidratado e depositado no acervo do Herbário da Amazônia Meridional. Para as análises relacionadas aos aspectos reprodutivos, foram coletados flores e botões florais em diferentes estágios de desenvolvimento, os quais foram utilizados para a caracterização floral, índice meiótico, citoquímica e viabilidade polínica. Os resultados demonstram que E. poeppigiana apresenta inflorescências em pseudoracemos terminais com flores vistosas, alta taxa de viabilidade polínica (92,37\% - 96,07\%) que foi concordante com a alta porcentagem do índice meiótico (90,56\%), sugerindo estabilidade e regularidade meiótica, além de possuir amido e lipídeo como substâncias de reserva. Os corantes reativos de Alexander e carmim acético $2 \%$ são recomendados para análises de viabilidade polínica da espécie. O presente estudo reafirma a ocorrência de E. poeppigiana para a flora do Estado de Mato Grosso.

\section{Morphology, meiotic index, polynic viability and cytochemistry of Erythrina poeppigiana (Walp.) O. F. Cook}

\begin{abstract}
Erythrina poeppigiana (Walp.) O. F. Cook. is a tree species belonging to the family Leguminosae (Papilionoideae). It is intercropped in cocoa plantations as it is a deciduous species and has landscaping potential due to the exuberance of the flowers, however there are few studies on this species. The objective of this work was to verify the morphology of Organs vegetative and reproductive organs, meiotic index, pollen viability and cytochemical composition of the pollen grain of $E$. poeppigiana. They were collected from fertile branches of the species naturally occurring in the rural area of the municipality of Alta Floresta, Mato Grosso. The material was herborized, dehydrated and deposited in the collection of the Herbário da Amazônia Meridional. For analyzes related to reproductive aspects, flowers and flower buds were collected at different stages of development, which were used for floral characterization, meiotic index, cytochemistry and pollen viability The results show that E. poeppigiana has terminal pseudoracemous inflorescences with showy flowers, a high rate of pollen viability (92,37\% - $96,07 \%$ ) which was in agreement with the high percentage of the meiotic index (90,56\%), suggesting stability and meiotic regularity, in addition to having starch and lipid as reserve substances. Reactive dyes from Alexander and $2 \%$ acetic carmine are recommended for analysis of pollen viability of the species. The present study reaffirms the occurrence of E. poeppigiana for the flora of the State of Mato Grosso.
\end{abstract}

Keywords: Fabaceae; Floral biology; Mulungu.

Ana Paula Roveda (iD

Universidade do Estado de Mato Grosso, Brasil http://lattes.cnpq.br/7253460466001147 http://orcid.org/0000-0003-4752-7128 anapaularoveda@hotmail.com

José Martins Fernandes (it)

Universidade do Estado de Mato Grosso, Brasil http://lattes.cnpq.br/2858846943252297 http://orcid.org/0000-0002-8264-5085 fernanbio@bol.com.br

\section{Auana Vicente Tiago}

Universidade do Estado de Mato Grosso, Brasil http://lattes.cnpq.br/3112795576497501 http://orcid.org/0000-0001-9556-9491 auanabio@hotmail.com

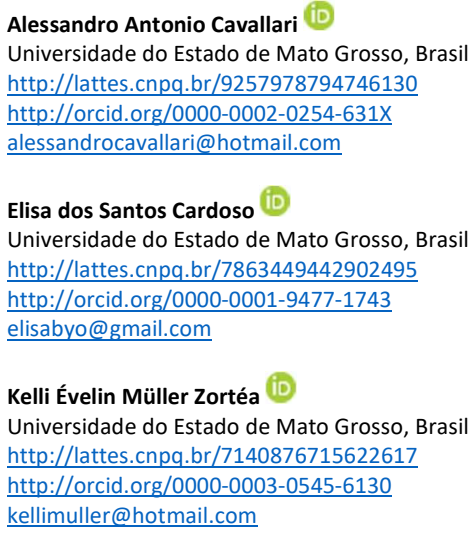

Ana Aparecida Bandini Rossi (D) Universidade do Estado de Mato Grosso, Brasil http://lattes.cnpq.br/2734433144153549 http://orcid.org/0000-0002-8318-5375 anabanrossi@gmail.com

\section{Referencing this:}

ROVEDA, A. P.; FERNANDES, J. M.; TIAGO, A. V.; CAVALLARI, A. A.; CARDOSO, E. S.; ZORTÉA, K. É. M.; ROSSI, A. A. B.. Morfologia, índice meiótico, viabilidade polínica e citoquímica de Erythrina poeppigiana (Walp.) O. F. Cook. Revista Ibero Americana de Ciências Ambientais, v.12, n.6, p.602-614, 2021. DOI: http://doi.org/10.6008/CBPC21796858.2021 .006 .0050

DOI: 10.6008/CBPC2179-6858.2021.006.0050 


\section{INTRODUÇÃO}

A espécie Erythrina poeppigiana (Walp.) O. F. Cook. pertence à família Leguminosae, subfamília Papilionoideae. Leguminosae é uma das principais em número de espécies (JUDD et al., 2009), considerada a terceira maior família de angiopermas do mundo, sendo representada por 766 gêneros e cerca de 19.580 espécies, distribuídos em sete subfamílias, Duparquetioideae, Cercidoideae, Detarioideae, Dialioideae, Caesalpinioideae e Papilionoideae, sendo que Caesalpinioideae inclui os táxons de Mimosoideae, no clado Mimosoide (LEWIS et al., 2005; LPWG, 2017). No Brasil, ocorrem cerca de 246 gêneros e 2.999 espécies (BFG 2018). Em terras brasileiras está entre as principais famílias que compõem a flora dos diferentes ecossistemas (SOUZA et al., 2005).

O gênero Erythrina ocorre nas regiões tropicais e subtropicais do mundo e possui cerca de 120 espécies, das quais 70 estão na região Neotropical, sendo 50 espécies no México, América Central e Caribe e 20 espécies na América do Sul (VASCONCELOS et al., 2003; SCHRIRE, 2005). O nome Erythrina vem do grego "erythros", que significa vermelho, em alusão à cor de suas flores (SCHRIRE, 2005), no entanto existem outras cores de flores. No Brasil, é citada a ocorrência de 13 espécies, são elas: E. amazonica Krukoff, E. cristagalli L., E. dominguezii Hassl., E. falcata Benth., E. fusca Lour., E. mulungu Mart., E. poeppigiana (Walp.) O. F. Cook, E. similis Krukoff, E. speciosa Andr., E. ulei Harms, E. variegata L., E. velutina Willd. e E. verna Vell. (MARTINS, 2018).

As espécies de Erythrina possuem uma vasta diversidade morfológica, são arbustos ou árvores que apresentam algumas características que facilitam sua identificação, como folhas trifolioladas, estipelas glandulares na base dos folíolos, acúleos no caule, ramos e/ou folhas, inflorescência em pseudorracemos eretos ou pêndulos, flores em sua maioria com estandarte vermelho, rosa ou laranja, com exceção de algumas espécies que apresentam outras cores como amarelo esverdeado, branco ou pálido (NEILL, 1993; MARTINS, 2014).

Além das características macromorfológicas como folhas, flores e frutos, usadas na identificação das plantas, existem as micromorfológicas como os grãos de pólen, que variam morfológicamente de uma espécie para outra (ERDTMAN, 1966). O grão de pólen é produzindo nas anteras, com morfologia variada e uma parede quimicamente estável que protege o gametófito masculino e reconhece o estigma compatível para germinação (SOLER et al., 2002).

Conhecimentos sobre aspectos reprodutivos de uma planta colaboram para práticas que visam a conservação da espécie, implementação de sistemas de produção e programas de melhoramento genético (ZEN et al., 2005; POZZOBON et al., 2015). Para espécies vegetais que se reproduzem de forma sexuada, o grão de pólen é responsável por transportar o gameta masculino para o gameta feminino (AGOSTINI et al., 2014), desempenhando importante papel na reprodução e produtividade da planta (SOUZA et al., 2014; OLIVEIRA et al., 2014). Dessa forma, o sucesso reprodutivo depende de polens viáveis, oriundos do processo meiótico que ocorre nas anteras (PATEL et al., 2014).

É durante a meiose que ocorre a recombinação dos genes e os eventos da gametogênese são 
controlados por um grande número de genes. A meiose é considerada uma fonte de variabilidade genética que os organismos possuem para se adaptar ao meio ambiente em que vivem e, dessa forma, garantir a sua perpetuação através da descendência (GOLUVBOVSKAYA, 1979; SINGH, 1993; NASSAR et al., 2006; PAGLIARINI, 2000).

O processo meiótico regular gera gametas viáveis e, normalmente, uma alta porcentagem de grãos de polens viáveis é esperada, tendo como resultado um alto percentual de tétrades normais (TECHIO et al., 2005). Anormalidades que ocorrerem durante a meiose levam à formação de gametas com um número de cromossomos não balanceado o que geralmente o torna inviável (NASCIMENTO et al., 2014), tendo como consequência a infertilidade da planta (PAGLIARINI, 2000).

Estudos de estabilidade meiótica e viabilidade dos grãos de pólen permitem indicar o potencial de cruzamento da planta, sendo o índice meiótico (IM) criado para avaliar a estabilidade meiótica dos genótipos analisando os produtos pós-meióticos como as tétrades, tríades, díades, mônades e políades (LOVE, 1951).

O estudo da viabilidade polínica, por sua vez, é de grande importância para programas de melhoramento vegetal e, a partir dessa informação, é possível obter correlações com anormalidades meióticas, auxiliar na seleção de materiais genéticos e fazer inferências sobre a eficiência de cruzamentos (BIONDO et al., 2001).

Habitualmente, a classificação e visualização dos grãos de pólen são realizadas por meio da microscopia óptica (CORREIA, 2016). À avaliação da viabilidade polínica pode ser analisada através de testes de coloração dos quais usam corantes químicos específicos que reagem com componentes celulares presentes nos grãos de pólen maduros (ALMEIDA et al., 2011; PAGLIARINI et al., 2005).

Os componetes de reservas presentes nos grãos de pólen também podem ser determinados por meio de testes colorimétricos. Esse tipo de análise conhecida como citoquímica, utiliza corantes como o lugol e sudan IV que identificam a presença de amido e lipídeos, respectivamente (PAGLIARINI et al., 2005). A presença de amido no grão de pólen é uma adaptação das plantas que evita o ataque de insetos não polinizadores que se alimentam de pólen, bem como a presença de lipídeos é uma adaptação das plantas que atrai polinizadores, especialmente abelhas (BAKER et al., 1979).

Diante do exposto, o presente trabalho objetivou fazer um estudo reprodutivo, focando na morfologia dos órgãos vegetativos e reprodutivos, determinação do índice meiótico, viabilidade polínica e composição citoquímica do grão de pólen de Erythrina poeppigiana.

\section{MATERIAIS E MÉTODOS}

\section{Área de Estudo}

O material de estudo foi coletado na comunidade Ouro Verde e São Bento, localizadas na zona rural de Alta Floresta, município com área de $8.953,213 \mathrm{~km}^{2}$, situado no extremo Norte de Mato Grosso, à $830 \mathrm{Km}$ da capital do estado, Cuiabá. Segundo Alvares et al. (2013), o clima da região é tropical chuvoso, com estação seca e chuvosa definida; a temperatura média anual varia entre $19,6^{\circ} \mathrm{C}$ e $32,4^{\circ} \mathrm{C}$; o volume de precipitação 
pluviométrica é elevado ficando com média entre 2.500 e $3.100 \mathrm{~mm}$ ao ano.

A cobertura vegetal do município de Alta Floresta é formada em sua maioria por Floresta Ombrófila Aberta e Densa, Floresta Estacional Semidecidual e Decidual, no bioma Amazônia, que ocorre associada a palmeiras e cipós. Esse tipo de floresta é caracterizado pela presença de árvores de porte grande e bastante espaçadas, agrupamento de palmeiras e enorme quantidade de fanerófitas sarmentosas (OLIVEIRA, 2006; ZAPPI et al., 2011).

\section{Coleta e Herborização}

Ramos férteis de E. poeppigiana foram coletados nas comunidades Ouro Verde e São Bento, herborizados, desidratados de acordo com as técnicas tradicionais (FIDALGO et al., 1989; JUDD et al., 2009), identificados no Laboratório de Morfologia Vegetal do Herbário da Amazônia Meridional (HERBAM) da Universidade do Estado de Mato Grosso - Carlos Alberto Reyes Maldonado (UNEMAT) de acordo com literatura especializada (MARTINS, 2014) e depositados no acervo do HERBAM.

\section{Fixação e Estocagem das Flores e Botões}

Foram coletados botões florais, de quatro indivíduos de E. poeppigiana na comunidade Ouro Verde, em diferentes tamanhos e estágios de desenvolvimento para a realização do índice meiótico, viabilidade polínica e composição citoquímica do grão de pólen. Os botões de cada indivíduo foram armazenados em frascos de vidro devidamente etiquetados, fixados em etanol e ácido acético, na proporção 3:1, e mantido em temperatura ambiente por 24 horas, sendo transferidos para álcool 70\% e mantidos sob refrigeração até a sua utilização. As análises foram realizadas no Laboratório de Genética Vegetal e Biologia Molecular e no Laboratório Didático I da UNEMAT, campus de Alta Floresta-MT.

Foram coletadas flores de quatro indivíduos de E. poeppigiana, fixadas e armazenadas conforme metodologia empregada para os botões florais, diferindo-se por não serem armazenadas por indivíduo e sim em um mix. As análises foram realizadas no Laboratório de Morfologia Vegetal do HERBAM da UNEMAT, campus de Alta Floresta-MT.

\section{Diagnose Morfológica}

A diagnose morfológica da espécie foi realizada no Laboratório de Morfologia Vegetal do HERBAM, com base em caracteres vegetativos e reprodutivos dos espécimes coletados nas duas comunidades. Foi elaborada de acordo com os procedimentos usuais de taxonomia, por meio de análise macromorfológica do material coletado, com uso de um estereomicroscópio (Zeiss). As medidas foram obtidas a partir de cinco amostras para cada estrutura, utilizando-se papel milimetrado e régua. A nomenclatura empregada foi baseada em Radford et al. (1974) e Barroso et al. (1999).

A análise morfológica do material botânico incluiu as medidas dos órgãos vegetativas em material desidratado, enquanto que para as partes florais foi utilizado material estocado em álcool etílico $70 \%$ e reidratado. As abreviações apresentadas são: alt=altura, compr=comprimento, $\mathrm{cm}=$ centímetro, $\mathrm{m}=\mathrm{metro}$ e 
$\mathrm{mm}=$ milímetro.

\section{Índice Meiótico}

A análise do Índice Meiótico (IM) foi realizada por indivíduo, onde avaliou-se botões florais jovens através da observação das células em pós-meiose. Os botões florais foram mensurados com paquímetro digital, para identificar o tamanho dos que apresentavam produtos pós-meióticos.

Foram preparadas oito lâminas, sendo contabilizadas 300 células por lâmina, totalizando 2.400 produtos pós-meióticos por indivíduo. Para o preparo das lâminas utilizou-se a técnica de esmagamento das anteras para liberação do material, conforme proposto por Guerra et al. (2002), e coradas com, aproximadamente, $100 \mu \mathrm{l}$ de carmim acético $2 \%$. As contagens foram realizadas por meio da técnica de varredura sob microscópio óptico com aumento de 400x.

Tétrades com quatro células do mesmo tamanho foram consideradas normais e qualquer desvio (mônades, díades, tríades e políades) foram consideradas anormais. O índice meiótico (IM) foi calculado de acordo com Love (1951), onde: IM= (Número de tétrades normais/Número total de produtos pós-meióticos) $x 100$.

\section{Viabilidade Polínica}

A análise da viabilidade polínica foi realizada por indivíduo, onde as anteras dos botões florais foram colocadas sobre as lâminas usando a técnica de esmagamento para liberação dos grãos de pólen, descrita por Guerra et al. (2002). As anteras foram esmagadas com auxílio do bastão de vidro, sob, aproximadamente, $100 \mu \mathrm{l}$ de corante, sendo cobertas por uma lamínula. A coloração do pólen foi realizada por meio de dois corantes: carmim acético 2\% (PAGLIARINI et al., 2005) e reativo de Alexander (ALEXANDER, 1980). Para cada corante foram preparadas oito lâminas e analisadas 300 polens por lâmina, totalizando 2.400 polens por indivíduo.

As lâminas foram observadas por meio da técnica de varredura sob microscópio óptico com aumento de 400x. Com os dados obtidos, foi calculada a porcentagem de polens viáveis, onde: Viabilidade polínica (\%)= (Número de grãos de polens viáveis/Número de grãos de polens contados) x 100.

\section{Composição Citoquímica do Grão de Pólen}

A técnica de citoquímica foi realizada de acordo com o protocolo de Baker et al. (1979), onde os grãos de pólen de E. poeppigiana, foram submetidos a coloração com lugol e sudan IV para verificar a presença de amido e lipídeos, respectivamente.

Para o preparo das lâminas foi realizado um mix com os botões dos quatro indivíduos de $E$. poeppigiana amostrados, onde as anteras foram esmagadas para a liberação dos grãos de pólen, conforme a técnica proposta por Guerra et al. (2002). As anteras foram esmagadas com auxílio do bastão de vidro, sob, aproximadamente, $100 \mu \mathrm{l}$ de corante, sendo cobertas por uma lamínula e posteriormente observadas por meio da técnica de varredura sob microscópio óptico com aumento de 400x. Para cada corante foram 
preparadas oito lâminas e analisadas 300 polens por lâmina, totalizando 2.400 polens por corante.

\section{Análises Estatísticas}

Os dados do índice meiótico (IM) e da viabilidade polínica foram organizados e calculados utilizandose o programa Microsoft Excel (2016), estes foram submetidos à análise de variância (ANOVA), e as médias comparadas ao teste de Tukey a 1\% de probabilidade pelo programa estatístico Genes (CRUZ, 2016).

\section{RESULTADOS E DISCUSSÃO}

\section{Estudo Morfológico}

Erythrina poeppigiana (Walp.) O. F. Cook, U.S.D.A. Div. Bot. Bull. 25: 57. 1901. Figura 1A-I. Nome popular: eritrina-do-alto, suína, mulungu-do-alto, mulungu.

Árvores, 7-22 m alt., caducifólias; ramos jovens tomentosos a estrigosos; estípulas 2,8-3,5 mm compr., triangulares, caducas. Folhas alternas, trifolioladas; pulvino 0,6-0,9 cm compr.; pecíolo 8,2-16,3 cm compr., subcilíndrico, glabrescente; 2 estipelas glandulares nos folíolos laterais, estipitadas, cilíndricas, ausente no folíolo terminal; raque 3,6-4,7 cm compr., subcilíndrica, glabrescente; pulvinulos 1,1-1,6 cm compr.; folíolos 9,3-15,3 × 11,9-15 cm, amplamente ovado, ápice agudo a obtuso, base truncada a obtusa; faces adaxial e abaxial glabras a glabrescentes. Inflorescências em pseudoracemos terminais, pedúnculo 26,8 cm compr., raque 7-18 cm compr.; brácteas 1,5-2 mm compr., ovadas, seríceas, caducas; pedicelo 0,91,3 cm compr.; bractéolas $1 \mathrm{~mm}$ compr., ovadas, seríceas, caducas. Flores vistosas, 5-meras; cálice 0,8-0,9 cm compr., campanulado, carnoso, verde com bordas alaranjadas, curtamente seríceo, giba presente, apícula ausente; estandarte 4,7-4,9 × 2,2-2,3 cm, elíptico, ápice retuso, base atenuada, esparsamente puberulento, laranja, alas 1,3-1,4 cm compr., obovadas, ápice obtuso, base atenuada, laranja, pétalas da quilha 3,8-4 × 0,7-1 cm, unidas, falcadas, ápice arredondado, base atenuada, laranja; androceu diadelfo (9+1), tubo estaminal 3,6-4,4 cm compr., avermelhado, anteras 2,5-1 $\mathrm{mm}$ compr., dorsifixas, elípticas; nectário composto por 9 lóbulos delgados, carnosos; ginóforo 1,5-1,9 cm compr.; ovário 2,2-2,5 cm compr., subcilíndrico, glabro; estilete 0,7-0,9 cm compr., glabro; estigma capitado. Legumes imaturos.

Material examinado: Brasil. Mato Grosso. Alta Floresta, Comunidade Ouro Verde, 13.VII.2018, fl., A. P. Roveda 01 (HERBAM); Comunidade São Bento, fazenda do Sr. Devanir, 19.VII.2020, fl., J.M. Fernandes 1691 (HERBAM), chácara do Zeca, 18.VIII.2020, fl., J. M. Fernandes 1709 (HERBAM), Sítio Novo Plano, 18.VIII.2020, fl., J. M. Fernandes 1710 (HERBAM).

Erythrina poeppigiana ocorre na Bolívia, Brasil, Colômbia, Equador, Panamá, Peru e Venezuela (KRUKOFF, 1939; MARTINS, 2014). No Brasil, a ocorrência da espécie é citada para os estados do Acre, Amazonas, Pará e Rondônia, norte do país, no domínio fitogeográfico da Amazônia (MARTINS, 2014; MARTINS, 2020). Na Flora do Brasil 2020 - Algas Fungos a espécie, E. poeppigiana não é citada para o Estado de Mato Grosso, no entanto, Borges et al. (2014) citam a sua ocorrência para a flora do estado. 


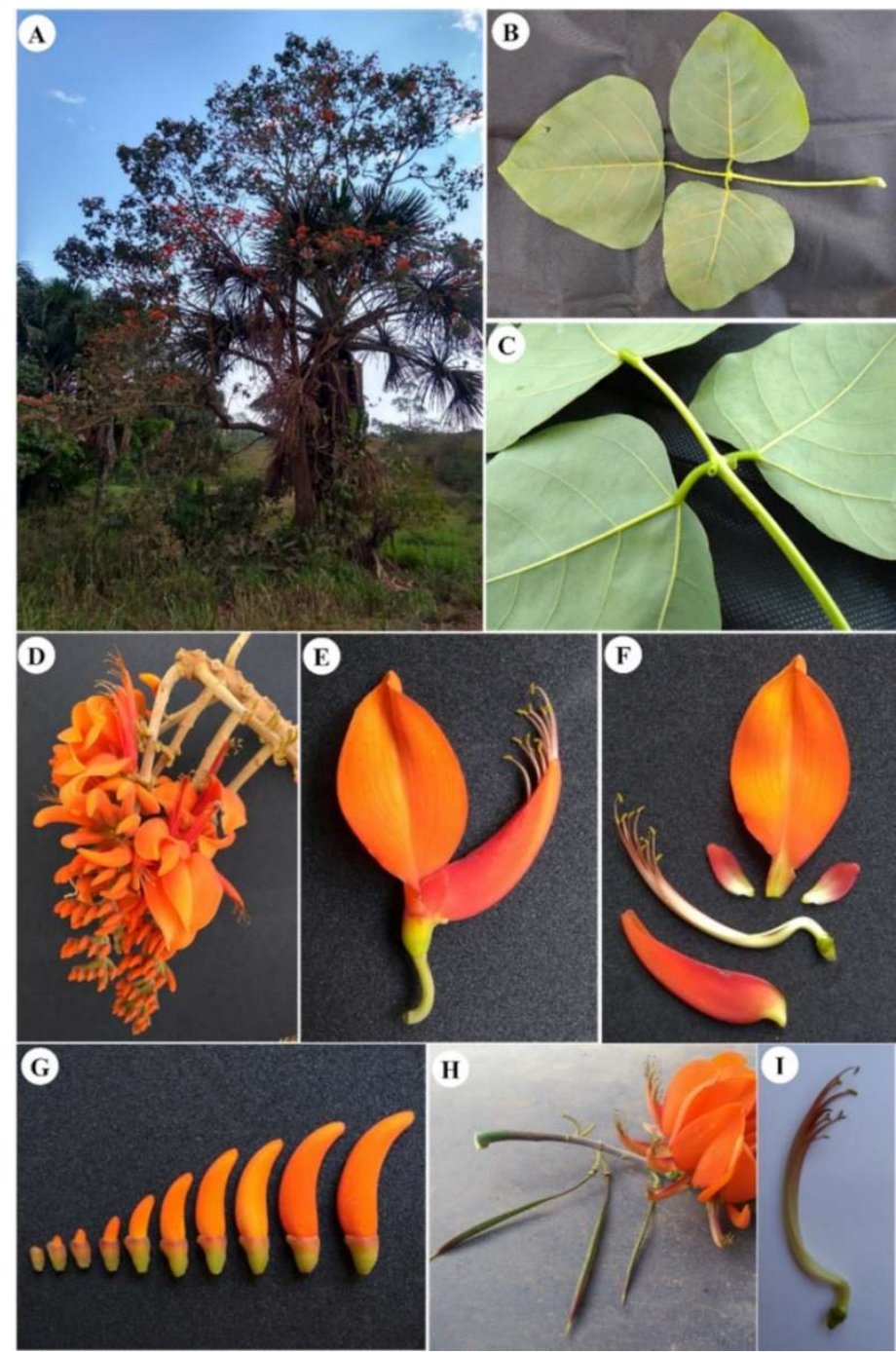

Figura 1: Erythrina poeppigiana: hábito (A), folha (B), estipelas com nectários nos folíolos laterais (C), inflorescência $(D)$, flor $(E)$, morfologia externa da flor $(F)$, botões florais $(G)$, flores e legumes imaturos $(H)$, androceu e gineceu (I).

No Brasil, vem sendo utilizada na construção de cercas ecológicas (MATOS et al., 2005). Devido ao seu uso na agricultura, é uma das espécies mais conhecidas do gênero, sendo introduzida na América Central para sombreamento nas plantações de cacau e café (NEILL, 1993). No mundo a espécie é muito utilizada em sistemas agroflorestais (RUSSO, 1993).

A árvore é decídua, de copa aberta e arredondada, muito florífera e ornamental, com grande resistência à seca, apresentando rusticidade e podendo ser usada para recuperação de áreas degradadas (LORENZI, 2008). Usada para arborização de parques e praças públicas, sombreamento dos cacaueiros, confecção de tamancos e de jangadas (LIMA, 1989). Floresce de julho a agosto e frutifica de agosto a setembro, sendo os pássaros os principais agentes polinizadores (SOSSELLA et al., 2008).

\section{Índice Meiótico}

O tamanho médio dos botões florais com células em pós-meiótico variou de 8,88 a 9,73 mm. O Índice Meiótico médio apresentado por E. poeppigiana foi de 90,56\%. Quando as análises foram realizadas por indivíduo, observa-se que AF4 apresentou a maior média de regularidade meiótica, não se diferindo estatisticamente de AF2; AF1, por sua vez, apresentou a menor média de IM, diferindo estatisticamente dos 
demais (Tabela 1).

Tabela 1: Número de tríades anormais e tétrades normais, e médias de índice meiótico (IM) em populações de Erythrina poeppigiana.

\begin{tabular}{llll}
\hline Individuos & Tríades & Tétrades & IM (\%) \\
\hline AF1 & 362 & 2038 & $84,91 \mathrm{c}$ \\
AF2 & 188 & 2212 & $92,16 \mathrm{ab}$ \\
AF3 & 232 & 2168 & $90,12 \mathrm{~b}$ \\
AF4 & 119 & 2281 & $95,04 \mathrm{a}$ \\
\hline TOTAL & 901 & 8699 & \\
\hline Média & & & 90,56 \\
\hline CV (\%) & & & 3,66 \\
\hline
\end{tabular}

Médias seguidas de letras minúsculas na vertical não diferem entre si pelo teste de Tukey a 1\% de significância.

Os individuos AF2, AF3 e AF4 apresentaram IM superiores a $90 \%$ o que indica alta regularidade meiótica. Pereira et al. (2017) apontam que o índice meiótico comprova a estabilidade da meiose, uma vez que o mesmo indica o quanto a divisão celular meiótica foi regular e estável. Já o IM do indivíduo AF1 ficou abaixo do indicado por Love (1951), onde relata que genótipos com índice meiótico abaixo de 90\% não são indicados para cruzamentos, pois, podem apresentar problemas reprodutivos, por serem citologicamente instáveis. E esse resultado pode estar relacionado ao fato do indivíduo AF1 estar isolado em uma área de pastagem, diferentemente dos demais indivíduos analisados que se encontram próximos e com outras espécies vegetais ao entorno, para Sun et. al (2014), as condições de stresses abióticos podem influenciar negativamente na meiose e na viabilidade polínica.

A anormalidade encontrada neste estudo foi a presença de tríades, (Figura 2A), sendo que produtos pós-meióticos como mônades, díades e políades não foram observados. Esse tipo de anormalidade está relacionado com a divisão assincrônica e a desorientação das fibras do fuso, bem como outras irregularidades que podem ocorrer durante a meiose (SOUZA et al., 2011).

Horner et al. (1995), relatam que as anormalidades meióticas influenciam nos produtos pósmeióticos, todavia, as anormalidades observadas em E. poeppigiana não prejudicaram de modo geral os produtos pós-meióticos da espécie, na qual apresentou IM de 90,56\% e conforme Love (1951), plantas com IM acima de 90\% apresentam alta estabilidade meiótica.
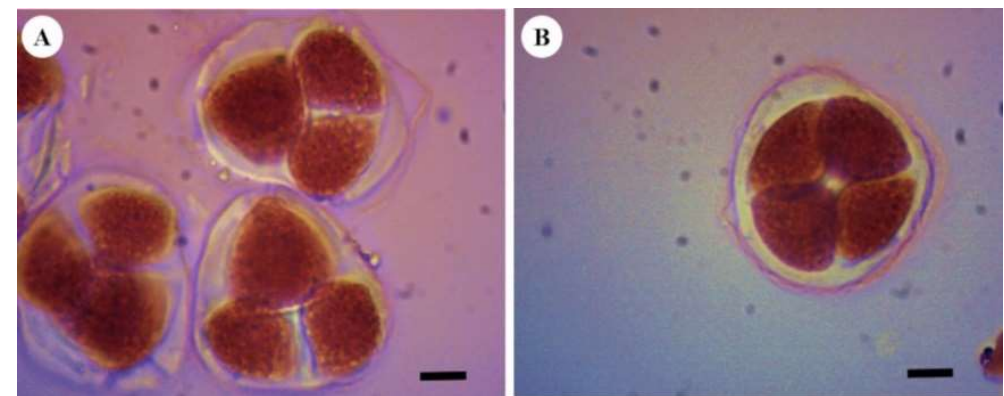

Figura 2: Produtos pós-meióticos de Erythrina poeppigiana. Tríade (A) e Tétrade (B). Barra: $10 \mu \mathrm{m}$

Resultados semelhantes ao deste trabalho foram obtidos para $E$. fusca, onde o índice meiótico foi de $98,45 \%$, apresentando um número maior de tétrades normais e uma pequena taxa de tríades, o que indica baixos níveis de irregularidades meióticas no gênero (BISPO et al., 2020). 


\section{Viabilidade Polínica}

Tanto o reativo de Alexander como o carmim acético 2\%, se mostraram eficientes para distinguir os polens viáveis dos inviáveis da espécie E. poeppigiana (Figura 3).
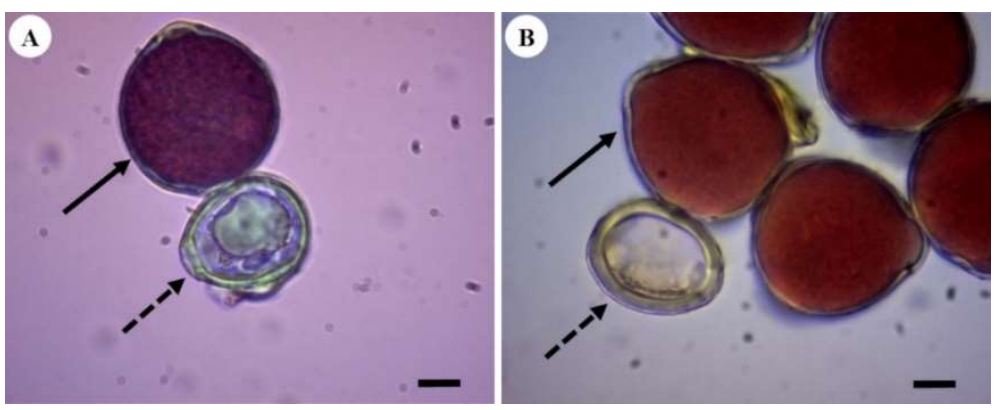

Figura 3: Grãos de pólen de Erythrina poeppigiana corados com reativo de Alexander (A) e carmim acético 2\% (B). Seta contínua: polens viáveis; seta tacejada: polens inviáveis. Barra: $10 \mu \mathrm{m}$.

Nas lâminas coradas com reativo de Alexander, os polens viáveis apresentaram o protoplasma corado de púrpura e a parede celular de verde e os polens inviáveis corados de verde, uma vez que não possuíam protoplasma (Figura 3A) (ALEXANDER, 1980).

Já as lâminas coradas com carmim acético 2\%, apresentaram os grãos de pólen viáveis corados de vermelho e os inviáveis sem coloração, devido o corante indicar a integridade da cromatina que ocorre apenas em grãos de polens viáveis (Figura 3B) (PAGLIARINI et al., 2005).

Tanto o reativo de Alexander como o carmim acético 2\% permitem avaliar a integridade de estruturas celulares como núcleo e parede celular (PEÑALOZA et al., 2005). Ambos corantes demonstraram ser indicados para estimar a viabilidade polínica da espécie, por apresentarem médias acima de $90 \%$. Souza et al. (2002) consideram que médias acima de 70\% indicam alta viabilidade do grão de pólen, e quanto maior for a viabilidade, mais eficaz será a fertilização da espécie.

Resultados semelhantes foram descritos por Oliveira et al. (2018) e por Bispo et al. (2020), em estudos desenvolvidos com Eugenia involucrata e Erythrina fusca, respectivamente, onde a porcentagem de viabilidade dos grãos de pólen foram superiores a 90\% utilizando o mesmo teste colorimétrico.

Quando as análises foram realizadas por indivíduo observa-se que o reativo de Alexander identificou a maior porcentagem de viabilidade polínica para os indíviduos AF2 e AF3. Esses mesmos indivíduos também se destacaram com maiores porcentagens de viabilidade quando análisado com o corante carmim acético 2\% (Tabela 2). Para o corante reativo de Alexander, entre os indivíduos AF1 e AF4, não foram observados diferenças estatísticas, porém para o carmim acético observa-se uma redução na viabilidade para os indivíduos AF1 e AF4, sendo o individuo AF1 com menor média de polens viáveis, diferindo-se estatisticamente dos demais individuos e também do reativo de Alexander (Tabela 2), corroborando com o maior número de inrregularidades meióticas observadas para este indivíduo. Nascimento et al. (2014) relatam que inrregularidades nos produtos pós-meióticos podem gerar gametas inviáveis.

Tabela 2: Médias percentuais da viabilidade polínica em genótipos de Erythrina poeppigiana coletados no município de Alta Floresta-MT.

\begin{tabular}{lll}
\hline Indivíduos & Reativo de Alexander & Carmim Acético
\end{tabular}




\begin{tabular}{lll}
\hline AF1 & $93,79 \mathrm{Ab}$ & $84,08 \mathrm{Bc}$ \\
AF2 & $97,87 \mathrm{Aa}$ & $96,75 \mathrm{Aa}$ \\
AF3 & $98,70 \mathrm{Aa}$ & $98,12 \mathrm{Aa}$ \\
$\mathrm{AF} 4$ & $93,91 \mathrm{Ab}$ & $90,50 \mathrm{Bb}$ \\
\hline $\mathrm{CV}(\%)$ & 1,55 & 3,31 \\
\hline
\end{tabular}

Médias seguidas das mesmas letras maiúsculas na horizontal e minúsculas na vertical não diferem estatisticamente entre si pelo teste Tukey a $1 \%$ de probabilidade.

Branbatti et al. (2016), ressalta que a alta viabilidade polínica pode demonstrar o grau de estabilidade dos genótipos, contribuindo para pesquisas de melhoramento genético de espécies vegetais, possibilitando a escolha de indivíduos mais estáveis para realizar cruzamentos.

O alto percentual de viabilidade polínica obtido para E. poeppigiana foi concordante com a porcentagem do índice meiótico obtido para a espécie. Para Lima et al. (2016), o alto percentual de tétrades normais é resultado da meiose regular, apresentando assim alta viabilidade polínica. Segundo Battistin et al. (2002), o alto índice meiótico e de viabilidade polínica, constatam regularidade meiótica na microsporogênese da espécie e caso a mesma regularidade ocorra também na megasporogênese, a espécie não apresentará problemas em termos de viabilidade de sementes e produção, contribuindo para a manutenção de novas gerações.

\section{Composição Citoquímica do Grão de Pólen}

As análises colorimétricas realizadas com os corantes lugol e sudan IV indicam a presença de amido e lipídeo como material de reserva do grão de pólen E. poeppigiana (Figura 4).

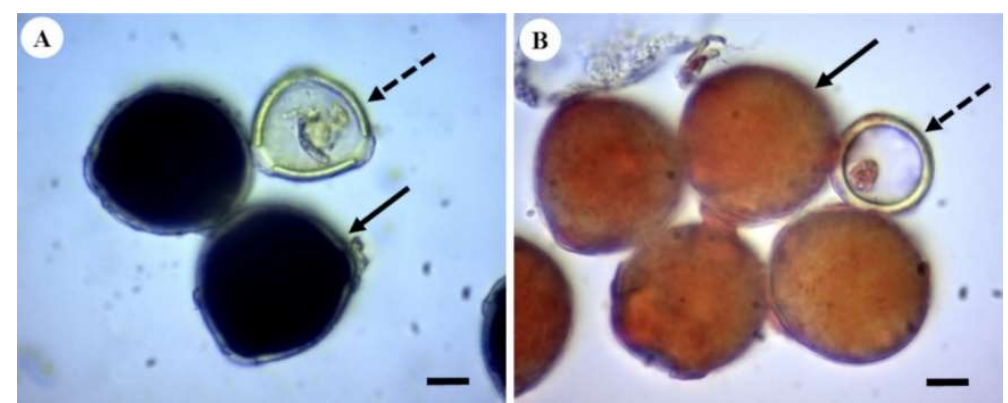

Figura 4: Grãos de pólen de Erythrina poeppigiana corados com lugol (A) (seta contínua: amido positivo; seta tracejada: amido negativo) e sudan IV (B) (seta contínua: lipídeo positivo; seta tracejada: lipídeo negativo). Barra: 10 $\mu \mathrm{m}$.

O lugol contém iodo que reage quimicamente com o amido presente no grão de pólen, dando coloração marrom escura, sendo classificado como amido positivo. Logo os polens que não apresentam amido ficam com coloração amarela clara e são classificados como amido negativo (Figura 4A) (BAKER et al., 1979; PAGLIARINI et al., 2005).

Já o sudan IV reage com o lipídeo, corando o grão de vermelho, sendo classificado como lipídeo positivo, enquanto os grãos de pólen que não apresentam coloração são classificados como lipídeo negativo, por não terem lipídeos como material de reserva (Figura 4B) (DAFNI, 1992).

A análise citoquímica resultou em uma média de $86,74 \%$ de grãos de pólen amido positivo e $97,17 \%$ de lipídeo positivo. Resultados semelhantes foram encontrados por Oliveira et al. (2020) em Theobroma speciosum e por Bispo et al. (2020) em Erythrina fusca, onde as espécies avaliadas apresentaram amido e 
lipídeo como substância reserva.

O amido pode ser totalmente ou parcialmente convertido em glicose, frutose, sacarose e pectinas, substâncias que aumentam a resistência dos grãos de pólen em ambientes adversos e auxiliam na germinação do tubo polínico, desta maneira o amido como substância de reserva é de suma importância para a manutenção da viabilidade dos polens (GUARCIA et al., 2003; PACINI et al., 2006). A presença de lipídeos auxilia na adesão dos grãos de pólen à antera e ao estigma, bem como, os protegem contra a perda de água e radiação ultravioleta (UV), além de mantê-los unidos durante o transporte (PACINI et al., 2005).

\section{CONCLUSÕES}

O presente estudo reafirmou a ocorrência da espécie E. poeppigiana para o estado de Mato Grosso, sendo que a diagnose morfológica e fotos de caracteres diagnósticos da espécie podem servir de base para futuros estudos taxonômicos e biogeográficos do gênero.

A espécie E. poeppigiana apresentou uma alta taxa de viabilidade polínica e alta porcentagem do índice meiótico, sugerindo estabilidade e regularidade meiótica. Os corantes reativo de Alexander e carmim acético $2 \%$ são recomendados para análises de viabilidade polínica da espécie.

As inrregularidades observadas nesse estudo não comprometeram a fertilidade da espécie $E$. poeppigiana, podendo ser incluida em futuros programas de melhoramento genético. A análise citoquímica indicou que E. poeppigiana possui amido e lipídeo como substância reserva em seus grãos de pólen.

\section{REFERÊNCIAS}

AGOSTINI, K.; LOPES, A. V.; MACHADO, I. C.. Recursos florais. In: RECH, A. R.; AGOSTINI, K.; OLIVEIRA, P. E.; MACHADO, I. C.. Biologia da polinização. Rio de Janeiro: Projeto Cultural, 2014. p.517.

ALEXANDER, M. P.. A versatile stain for pollen fungi, yeast and bacteria. Stain Technology, v.55, n.1, p.13-18, 1980. DOI: http://doi.org/10.3109/10520298009067890

ALMEIDA, C.; AMARAL, A. L.; NETO, J. F. B.; SERENO, M. J. C. $M$.. Conservação e germinação in vitro de pólen de milho (Zea mays subsp.mays). Revista Brasileira de Botânica, v.34, n.4, p.493-497, 2011. DOI: http://dx.doi.org/10.1590/S0100$\underline{84042011000400003}$

ALVARES, C. A.; STAPE, J. L.; SENTELHAS, P. C.; GONÇALVES, J. L. M.; SPAROVEK, G.. Köppen's climate classification map for Brazil. Meteorologische Zeitschrift, v.22, n.6, p.711-728, 2013. DOI: http://doi.org/10.1127/0941-2948/2013/0507

BAKER, H. G.; BAKER, I.. Starch in angiosperm pollen grains and its evolutionary significance. American Journal of Botany, v.66, n.5, p.591-600, 1979. DOI:

http://doi.org/10.1002/j.1537-2197.1979.tb06262.x

BARROSO, G. M.; MORIM, M. P.; PEIXOTO, A. L.; ICHASSO, C. L. F.. Frutos e sementes: morfologia aplicada a sistemática de dicotiledôneas. Viçosa: Imprensa Universitária, 1999.

BATTISTIN, A.; MATTOS, A. C. F.. Número de cromossomos, comportamento meiótico e viabilidade do pólen em três espécies de Stylosanthes sw. (leguminosae-papilionoideae) nativas do sul do Brasil. Bioikos, v.16, p.13-17, 2002.

BFG. The Brazil Flora Group. Brazilian Flora 2020: Innovation and collaboration to meet Target 1 of the Global Strategy for Plant Conservation (GSPC). Rodriguésia, v.69, n.4, p.15131527, 2018. DOI: http://doi.org/10.1590/2175$\underline{7860201869402}$

BIONDO, E.; BATTISTIN, A.. Comparação da eficiência de diferentes corantes na estimativa de viabilidade de grãos de pólen em espécies do gênero Eriosema (DC.) G. Don e Rhynchosia Lour (Leguminosae - Faboideae), nativas da região sul do Brasil. Bioikos, Campinas, v.15, n.1, p.39-44, 2001.

BISPO, R. B.; ROSSI, A. A. B.; ZÓRTEA, K. E. M.; PEDRI, E. C. M.; SANDER, N. L.; SILVA, C. J.. Morfologia, viabilidade polínica e índice meiótico em Erythrina fusca lour. Magistra, v.31, p.479-489, 2020.

BORGES, H. B. N.; SILVEIRA, E. A.; VENDRAMIN, L. N.. Flora arbórea de Mato Grosso: tipologias vegetais e suas espécies. Cuiabá: Entrelinhas, 2014.

BRANBATTI, A.; BRAMMER, S. P.; WIETHÖLTER, P.; NASCIMENTO JUNIOR, A.. Estabilidade genética em triticale estimada pela viabilidade polínica. Instituto Biológico, v.83, p.1-7, 2016. DOI: http://doi.org/10.1590/18081657000802014 
CORREIA, F. C. S.. Pólen coletado por Melipona eburnea (Apidae, Meliponina) em Rio Branco, Acre. Dissertação (Mestrado em Ciência Animal) - Universidade Federal do Acre, Rio Branco, 2016.

CRUZ, C. D.. Genes Software: extended and integrated with the R, Matlab and Selegen. Acta Scientiarum, v.38, n.4, p.547-552, 2016. DOI:

http://dx.doi.org/10.4025/actasciagron.v38i4.32629

DAFNI, A.. Pollination ecology: a practical approach. New York: Imprensa da Universidade de Oxford, 1992.

ERDTMAN, G.. Pollen morphology and plant taxonomy: Angiosperms. New York: Hafner Publishing Company, 1966.

FIDALGO, O.; BONONI, V. L. R.. Técnicas de coleta, preservação e herborização do material botânico. São Paulo: Instituto de Botânica, 1989.

GOLUVBOVSKAYA, I. N.. Genetics control of meiosis. International Review of Cytology, v.58, p.247-90, 1979. DOI: http://doi.org/10.1016/S0074-7696(08)61477-1

GUARCIA, M. I. R.; RANI-ALAOUI, M.; FERNANDEZ, M. C.. Behavior of storage lipids during development and germination of olive (Olea europaea L.) pollen. Protoplasma, v.221, p.237-244, 2003.

GUERRA, M.; SOUZA, M. J.. Como observar cromossomos: um guia de técnicas em citogenética vegetal, animal e humana. Ribeirão Preto: FUNPEC, 2002.

HORNER, H. T.; PALMER, R. G.. Mechanisms of genic male sterility. Crop Science, v.35, p.1527-1535, 1995. DOI: http://doi.org/10.2135/cropsci1995.0011183X00350006000 $\underline{2 x}$

JUDD, W. S.; CAMPBELL, C. S.; KELLOGG, E. A.; STEVENS, P. F.; DONOGHUE, M. J.. Sistemática vegetal: um enfoque filogenético. 3 ed. Porto Alegre: Artmed, 2009.

KRUKOFF, B. A.. The American species of Erythrina. Brittonia, v.3 n.2, p.205-337, 1939.

LEWIS, G. P.; SCHRIRE, B.; MACKINDER, B.; LOCK, M.. Legumes of the world. Kew: Royal Botanic Gardens, 2005.

LIMA, D. A.. Plantas das caatingas. Academia Brasileira de Ciências. Rio de Janeiro, 1989.

LIMA, D. C.; G. T.; DOS REIS, G. B.; TECHIO, V. H.; DAVIDE, L. C.; ABREU, A. F. B.. A Implications of mitotic and meiotic irregularities in common beans (Phaseolus vulgaris L.). Genetics and molecular research: GMR, v.15, n.2, p.1-10, 2016. DOI: http://doi.org/10.4238/gmr.15027749

LORENZI, H.. Plantas medicinais no Brasil: nativas e exóticas. Nova Odessa: Plantarum, 2008.

LOVE, R. M.. Varietal differences in meiotic chromosomes behavior of Brazilian wheats. Agronomy Journal, Madison, v.43, n.2, p.72-76, 1951. Dol: http://doi.org/10.2134/agronj1951.00021962004300020005 $\underline{x}$

LPWG. The Legume Phylogeny Working Group. A new subfamily classification of the Leguminosae based on a taxonomically comprehensive phylogeny. Taxon, v.66, n.1, p.44-77, 2017. DOI: http://doi.org/10.12705/661.3

MARTINS, M. V.. Filogenia do gênero Erythrina L. (leguminosae, papilionoideae, phaseoleae) e revisão taxonômica das espécies ocorrentes no Brasil. Tese (Doutorado em Biologia Vegetal) - Universidade Estadual de Campinas, Campinas, 2014.

MARTINS, M. V.. Erythrina in Flora do Brasil 2020. Jardim Botânico do Rio de Janeiro, 2020.

MATOS, L. V.; CAMPELLO, E. F. C.; RESENDE, A. S.; PEREIRA, J A. R.; FRANCO, A. A.. Plantio de Leguminosas arbóreas para produção de moirões vivos e construção de cercas ecológicas. Embrapa Agroecologia, 2005.

NASCIMENTO, D.; SBAIS, P. G.; ALONSO-PEREIRA, A. R.; CANTO, A. F.; ROMAGNOLO, M. B.; ALBERTON, O.. Analysis of meiotic behavior in Cordia ecalyculata Vell. (Boraginaceae). Biotemas, v.27, n.4, p.21-27, 2014. DOI: http://doi.org/10.5007/2175-7925.2014v27n4p21

NASCIMENTO, L. S.; BENEVENUTI, A. S.; LEITE, D. M.; SILVA, M. D. D.; MIRANDA, D.; MELLO, V.; DAHMER, N.; KARSBURG, I. V.. Estimativa da viabilidade polínica e índice meiótico de Delonix regia. Estudos, Goiânia, v.41, n.1, p.83-88, 2014

NASSAR, N. M. A.; FREITAS, M.. Prospects of polyploidizing cassava, Manihot esculenta Crantz, by unreduced microspores. Plant Breending. n.116, p.195-7, 2006. DOI: http://doi.org/10.1111/j.1439-0523.1997.tb02179.x

NEILL, D.. The genus Erythrina: taxonomy, distribution and ecological differentiation. In: WESTLEY, S. B.; POWELL, M. H.. Erythrina in the New and Old Worlds. Nitrogen Fixing Tree Research Reports. 1993. p.15-25.

OLIVEIRA, A. S.. Qualidade do solo em sistemas agroflorestais em Alta Floresta-MT. Dissertação (Mestrado em Ciências do Solo e Nutrição de Plantas) - Universidade Federal de Viçosa, Viçosa, 2006.

OLIVEIRA, L. B. P.; PIERRE, P. M. O.. Índice meiótico e palinologia de cerejeira-do-mato (Eugenia involucrata DCMyrtaceae). Revista de Ciências Agroveterinárias, v.17, n.4, p.481-490, 2018. DOI: http://doi.org/10.5965/223811711732018481

OLIVEIRA, P. E.; MARUYAMA, P. K.. Sistemas reprodutivos. In: RECH, A. R.; AGOSTINI, K.; OLIVEIRA, P. E.; MACHADO, I. C.. Biologia da polinização. Rio de Janeiro: Projeto Cultural, 2014. p.517.

OLIVEIRA, U. A.; RODRIGUES, A. S.; CARDOSO, E. S.; PEDRI, E. C. M.; DARDENGO, J. F. E.; FAGUNDES, P. A. S.; BISPO, R. B.; ROSSI, A. A. B.. Ciências Biológicas: Campo Promissor em Pesquisa. In: OLIVEIRA JUNIOR, J. M. B. CAVÃO, L. B.. 3. Citoquímica e Viabilidade Polínica de Theobroma speciosum Willd. Ex Spreng (Malvaceae). Ponta Grossa: Atena, v.10, 2020. p.114-123.

PACINI, E.; GUARNIERI, M.; NEPI, M.. Pollen carbohydrates and water content during development, presentation, and dispersal: a short review. Protoplasma, v.228, p.73-77, 2006. 
PACINI, E.; HESSE, M.. Pollenkitt: its composition and functions. Flora, Aschaffenburg, v.200, p.399-415, 2005. DOI: http://doi.org/10.1016/j.flora.2005.02.006

PAGLIARINI, M. S.. Meiotic behavior of economically important plant species: The relantionship between fertility and male sterility. Genetics and Molecular Biology, Ribeirão Preto, v.23, n.4, p.997-1002, 2000. DOI: http://doi.org/10.1590/S1415-47572000000400045

\section{PAGLIARINI, M. S.; POZZOBON, M. T.. II Curso de} citogenética aplicada a recursos genéticos vegetais. Brasília: Embrapa Recursos Genéticos e Biotecnologia, 2005.

PATEL, R. G.; MANKAD, A. U.. In vitro pollen germination: a review. International Journal of Scientific Research. v.3, n.5, p.304-307, 2014

PEÑALOZA, A. P. S.. II Curso de citogenética aplicada a recursos genéticos vegetais. Brasília: Embrapa Recursos Genéticos e Biotecnologia, 2005.

PEREIRA, T. N. S.; GERONIMO, I. G. D. C.; ROSSI, A. A. B.; PEREIRA, M. G.. Passiflora cristalina and Passiflora miniata: meiotic characterization of two wild species for use in breeding. Crop Breeding and Applied Biotechnology, v.17, n.3, p.273-279, 2017. DOI: http://dx.doi.org/10.1590/198470332017v17n3n41

POZZOBON, M. T.; BIANCHETTI, L. B.; SANTOS, S.; CARVALHO, S. I. C.; REIFSCHNEIDER, J. B.; RIBEIRO, C. S. C.. Comportamento meiótico em acessos de Capsicum chinense Jacq. do Banco de Germoplasma da Embrapa, Brasil. Revista Brasileira de Biociências, v.13, n.2, p.96-100, 2015.

RADFORD, A. E.; DICKISON, W. C.; MASSEY, J. R.; BELL, C. R.. Vascular plant systematics. Harper \& Row, New York, p.891, 1974.

RUSSO, R. O.. The use of Erythrina species in the America. In: WESTLEY, S. B.; POWELL, M. H.. Erythrina in the New and Old Worlds. Hawaii: Nitrogen fixing tree association, 1993. p.28-45.

SCHRIRE, B. D.. Tribo Phaseoleae. In: LEWIS, G.; SCHRIRE, B. D.; MACKINDER, B.; LOCK, M.. Legumes of the world. Kew: Royal Botanic Gardens, 2005. p.393-431.

SINGH, R. J.. Plant cytogenetics. Urbana: University of Illinois, 1993.

SOLER J. B.; NOLLA J. M. R.. Introducción. In: VALEROSANTIAGO, A. L.; CADAHIA-GARCÍA, A.. Polinosis, Polen y Alergia. MRA, 2002. p.7-16.

SOSSEllA, A. G.; PETRY, C.; NIENOW, A. A.. Propagação da corticeira do banhado (Erythrina crista-galli L.) (Fabaceae) pelo processo de estaquia. Revista Árvore, v.32, n.1, p.163171, 2008. DOI: http://dx.doi.org/10.1590/S010067622008000100018

SOUZA, M. D. A.; SILVEIRA, G. F.; SILVA, M. A. S.; KARSBURG, I. V.. Estimativa da viabilidade polínica em indivíduos de Tabebuia impetiginosa e Tabebuia crysotricha (Mart. ex. DC.) Standl. (Bignoniaceae) através de métodos citoquímicos. Enciclopédia Biosfera, Centro Científico Conhecer, Goiânia, v.10, n.18, p.3864, 2014.

SOUZA, M. M.; PEREIRA, T. N. S.. Comportamento meiótico em espécies selvagens e domesticadas de Passiflora. Revista Brasileira de Botânica, v.34, n.1, p.63-72, 2011.

SOUZA, M. M.; PEREIRA, T. N. S.; MARTINS, E. R. Microsporogênese e microgametogênese associadas ao tamanho do botão floral e da antera e viabilidade polínica em maracujazeiro-amarelo (Passiflora edulis Sims f. flavicarpa Degener). Ciência e Agrotecnologia, Lavras, v.26, n.6, p.1209-1217, 2002.

SOUZA, V. C.; LORENZI, H.. Botânica sistemática: guia ilustrado para identificação das famílias de angiospermas da flora brasileira, baseado em APG II. Nova Odessa: Instituto Plantarum, 2005

SUN, M.; GROSS, K.; SCHIESTL, F. P.. Floral adaptation to local pollinator guilds in a terrestrial orchid. Annals of Botany, v.113, n.2, p.289-300, 2014. DOI: http://doi.org/10.1093/aob/mct219

TECHIO, V. H.; DAVIDE, L. C.; PEREIRA, A. V.. Genomicanalysis in Pennisetum purpurum X P. Glacumhybrids. Caryologia, Firenze, v.58, p.28-33, 2005.

VASCONCELOS, S. M. M.; OLIVEIRA, R. G.; CARVALHO, M.; RODRIGUES, A. C. P.; SILVEIRA, R. E.; FONTELES, F. M.; SOUSA, F. C.; VIANA, B. G. S.. Antinociceptive activities of the hydroalcoholic extracts from Erythrina velutina and Erythrina mulungu in mice. Biological Pharmaceutical Bulletin, v.26, n.7, p.946-949, 2003. DOI: http://doi.org/10.1248/bpb.26.946

ZAPPI, D. C.; SASAKI, D.; MILLIKEN, W.; IVA, J.; HENICKA, G. S.; BIGGS, N.; FRISBY, S.. Plantas vasculares da região do Parque Estadual Cristalino, norte de Mato Grosso, Brasil. Acta Amazonica, v.41, n.1, p.29-38, 2011. DOI: http://doi.org/10.1590/S0044-59672011000100004

ZEN, D. M.; ACRA, L. A.. Biologia floral e reprodutiva de Agapanthus africanus (L.) Hoffmanns (Liliaceae). Estudos de Biologia, v.27, n.59, p.35-40, 2005. DOI: http://dx.doi.org/10.7213/reb.v27i59.22710

A CBPC - Companhia Brasileira de Produção Científica (CNPJ: 11.221.422/0001-03) detém os direitos materiais desta publicação. Os direitos referem-se à publicação do trabalho em qualquer parte do mundo, incluindo os direitos às renovações, expansões e disseminaç̃̃es da contribuição, bem como outros direitos subsidiários. Todos os trabalhos publicados eletronicamente poderão posteriormente ser publicados em coletâneas impressas sob coordenação da Sustenere Publishing, da Companhia Brasileira de Produção Científica e seus parceiros autorizados. Os (as) autores (as) preservam os direitos autorais, mas não têm permissão para a publicação da contribuição em outro meio, impresso ou digital, em português ou em tradução. 